\title{
LA CONSTRUCCIÓN DE LA IDENTIDAD COSTARRICENSE EN LOS TEXTOS PLÁSTICOS Y LITERARIOS DE AMIGHETTI
}

\author{
Herbert Zamora Rodríguez
}

\begin{abstract}
RESUMEN
El enfoque al concepto de la identidad costarricense se alcanza en este artículo mediante la lectura de los textos plásticos y literarios de Francisco Amighetti, quien elabora una construcción de esa identidad con base en el ser humano, en su visión de los otros seres humanos, y de su vida, entendida como una relación transtextual con el contexto sociocultural.
\end{abstract}

\begin{abstract}
An aproach to a concept of Costa Rican identity is reached in this article through the reading of the literary and harmoniously conceived and executed texts of Francisco Amighetti, who elaborates a construction of that identity based on the human being, in the view he has of other humans, and of his own life, understood as a transtextual relationship within the sociocultural context.
\end{abstract}

Francisco Amighetti es uno de los artistas que mejor ha logrado penetrar en la intimidad del ser costarricense y plasmar su visión, a partir de su propia experiencia y de la reflexión sobre los procesos sociales, en sus textos plásticos y literarios, en los que se manifiestan los recuerdos de un contexto que fue su presente y las inquietudes de una sociedad en transición. Los textos artísticos de Amighetti son recreaciones articuladas de sus propias relaciones socioculturales. En ellos se hace evidente la imposibilidad de comprender la sociedad actual si se desvincula de un proceso de relación transtextual con el pasado.

Se encuentra, por lo tanto, en Amighetti, el tiempo nostálgico de un pasado que fue su presente y que intenta consolidar un modo de ser costarricense, ya manifiesto en diferentes construcciones, tales como el Himno Nacional, el campesino labriego sencillo y su modus vivendi, propio de la literatura costarricense en sus inicios. Su obra surge dentro de una tendencia cultural e intelectual en torno a un movimiento nacionalista que aparece en la literatura, las artes plásticas y la música.

El artista reproduce su medio, construyendo un corpus artístico en el que se refleja un imaginario social. Por lo tanto, se trata de textos testimoniales de un vivir en un presente irrepetible, que se transforma en pasado y participa de la gestación de una identidad personal y nacional, pero es también el presente marcado por la conciencia del devenir, una visión del futuro que altera la percepción del presente y produce inquietudes permanentes en sus textos plásticos y literarios. 
El tiempo de Amighetti es el tiempo asimilado desde una perspectiva Occidental, una medida objetiva y lineal que se va acumulando en el acontecer cotidiano en la cual aprendió a orientarse desde la infancia.

Sus textos son la manera de valorar lo próximo, de seleccionar los acontecimientos del fluir diario, para rescatar la memoria colectiva en un espacio temporal que lo define, constituyéndose este en una retícula de confluencias, actitudes y expectativas ante la patria que se construye ideológicamente.

La literatura y la plástica de Amighetti es testimonial, según me parece. Aunque se trata de testimonios que trascienden el nivel de la representación personal para rescatar como memoria colectiva, conciencia y proyecto estético (Zamora 1998: 1).

A partir del mismo texto, toda realidad se constituye en un anclaje con otros textos de la cultura, en relación con los cuales debe ser definida y comprendida. Estamos ante un sujeto colectivo, conformado y autoconformado por la textualidad de la cultura en constante dialogismo, como el mismo Amighetti lo revela en su texto poético:

\section{Busqué la Luz}

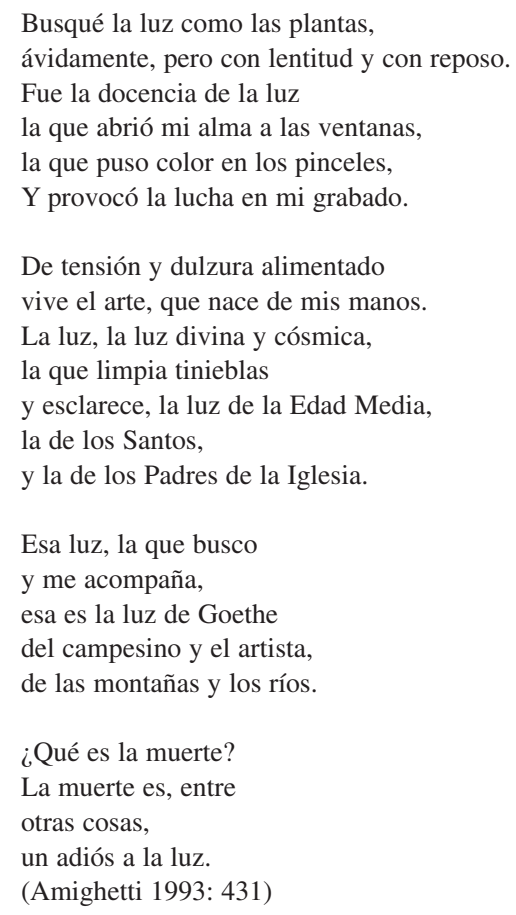

En este texto, se muestra la dicotomía y el maniqueísmo propios del pensamiento cristiano. Al igual que en Aristóteles, la luz se convierte en el signo identificador del espíritu. Tradicionalmente, esta ha sido el signo de la intelectualidad y del conocimiento histórico y cotidiano que en Amighetti se va dando pausadamente en el marco de la cultura. Además, el artista valora la docencia como una época enriquecedora de su vida, que le abre las puertas al 
saber, que alimenta su producción artística, la luz que limpia las tinieblas es la que persigue afanosamente Amighetti; es la luz que le permite estructurar y reestructurar los discursos, la luz de la vida que se contrapone al vacío de la muerte y la oscuridad, definida como un adiós a la luz. Así, la muerte a pesar del interdiscurso religioso del texto, se ubica en las tinieblas de la nada, motivo de la angustia que cuestiona el mismo sentido de la vida.

Sin duda es su formación humanista la que le permite establecer la óptica para interactuar y visualizar nuestra cultura a través de la ventana, como la penetración en la intimidad del ser costarricense. Es, además, la luz del saber que va más allá de los libros; la que está en la conciencia de sí mismo y en la observación de lo cotidiano.

\footnotetext{
"Conócete a tí mismo", ésta es la ciencia. Solo cuando el hombre haya adquirido el conocimiento de todas las cosas podrá conocerse a sí mismo. Pues las cosas no son más que las fronteras del hombre (Nietzsche 1993: 48).
}

Muy ligado a la luz, el signo de la ventana se encontrará continuamente en los textos del artista. El interés por la ventana nos remite a inicios del siglo XIX y al romanticismo. Así, la transparencia de la ventana permite el paso de la luz, signo del espíritu que se presenta en el interdiscurso simbolista que buscaba una comprensión metafísica.

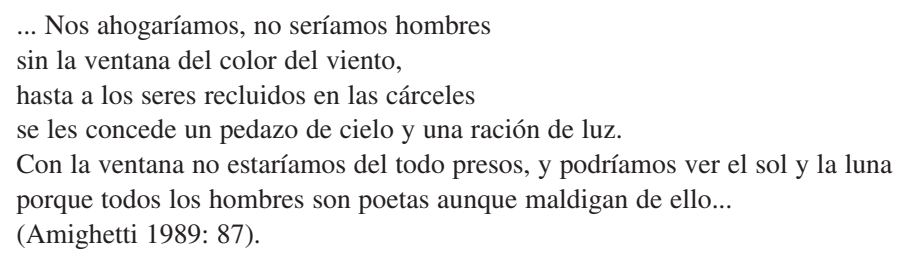

La ventana de Amighetti es el espacio que permite mirar desde fuera el interior del espacio arquitectónico, pero también permite, desde dentro, mirar el acontecer social. Este concepto tendrá su momento cumbre en La gran ventana, un texto plástico que Carlos Guillermo Montero considera como síntesis de su sensibilidad.

La necesidad de identificación social en el arte como elemento simbólico de unidad nacional aparece con vigor desde fines del siglo XIX, como una herencia del romanticismo, pero tendrá un gran impulso en la literatura con el texto Concherías, de Aquileo J. Echeverría, quien desarrolla el tema del campesino, "el concho”, y con El Moto, de Joaquín García Monge, quien introduce el interdiscurso del realismo social de Zolá y Tolstoi. Este libro de García Monge es, sin duda, un texto muy influyente, que provoca una ruptura en la literatura costarricense e introduce la tragedia humana del campesino costarricense.

No podemos dejar de lado los vínculos del artista con el acontecer internacional, principalmente en la década de los veinte, cuando en el contexto artístico el vanguardismo estético europeo pasaba por un período de regeneración. Sin embargo, los artistas de esta generación nacionalista estaban ávidos de nueva información, de lo que sucedía más allá de las fronteras nacionales, como lo señala el mismo Amighetti:

Los escultores Juan Manuel Sánchez y Francisco Zúñiga, la pintora Luisa González de Saenz, el pintor Manuel de la Cruz González y otros estábamos sedientos de conocer lo que pasaba en otras partes del mundo, las noticias nos llegaban con un enorme retraso, aunque talvéz había una ventaja: llegaba lo que había probado su vigencia al pasar por el filtro del tiempo. Así conocimos a Lembruck y Barlach, escultor, grabador 
y dramaturgo, a los artistas del Blau Reiter, al grupo de la Bauhaus con el arquitecto Gropius, a Paul Klee y a Kandisky, el maestro de la abstracción (Herra 1987:124).

Circulaban publicaciones como la Revista de Occidente, que sirvió como medio de difusión del pensamiento español, principalmente de la Generación del 27, la cual se aglutinó en torno al filósofo José Ortega y Gasset y su Deshumanización del arte, un texto que influyó fuertemente en esta generación.

El grupo llamado "Generación del 27" lo forman Pedro Salinas, Jorge Guillén, Gerardo Diego, Dámaso Alonso, Vicente Aleixandre, Federico García Lorca, Luis Cernuda y Rafael Alberti, entre otros. Estos sienten gran atracción por la poesía popular española, sobre todo los cancioneros y romanceros. Coincidieron con esta generación Pablo Picasso, Salvador Dalí y Luis Buñuel.

Situados entre la tradición y la renovación, ellos se sienten próximos a las vanguardias pero también próximos a la generación anterior: admiran a Juan Ramón Jiménez, Unamuno, Machado y Rubén Darío; sienten un auténtico fervor por los clásicos: Manrique, Garcilaso, San Juan de la Cruz, Fray Luis, Quevedo, Lope de Vega y, sobre todo, Góngora. Del $\mathrm{XIX}$, se apegan a Bécquer.

Debido a la longevidad de algunos autores y a los acontecimientos socioculturales y políticos que los hicieron evolucionar, como la Guerra Civil Española y la Segunda Guerra Mundial, los escritores de la Generación del 27 no se pueden encasillar en una corriente determinada.

En la década de los cuarenta, la poesía se llenó de pesimismo, para reflejar así la problemática del hombre contemporáneo y su angustia existencial ante las circunstancias adversas.

Estas mismas preocupaciones serán divulgadas en ciertos círculos intelectuales pero, sobre todo, en la revista Repertorio Americano, que circuló de 1919 a 1958, llenando el vacío intelectual de los costarricenses en una época de escasez de producción literaria, como lo señala el propio Amighetti:

\footnotetext{
El Repertorio Americano tuvo una influencia benéfica en varias generaciones. Su larga vida explica el alcance de su difusión, salía cuando podía, pero generalmente cada semana...En la segunda década del siglo surgían revistas de "vanguardia" con gran vitalidad y una existencia muy fugaz...En la época a que me refiero llegaban pocos libros y las traducciones se sucedían con gran lentitud. El Repertorio canalizó información no erudita, más bien vital y contemporánea, sobre todo de los valores americanos (Herra 1987: 119).
}

En la revista escribieron una serie de connotados escritores, entre los que se encontraban Ortega y Gasset y Miguel de Unamuno, que luego serán los maestros de la generación de 1931 en España, Gabriela Mistral, José de Vasconcellos, Pío Baroja, Pablo Neruda, Antonio Machado, Jorge Luis Borges y Nicolás Guillén, entre otros artistas de las vanguardias.

La incidencia de estos intelectuales en el contexto iberoamericano es indudable; de ahí la importancia de una revista de amplia difusión internacional en la cual pudieron participar varios intelectuales costarricenses, entre los cuales podemos citar a Eunice Odio, Carlos Luis Sáenz, Omar Dengo, Joaquín Gutiérrez, Yolanda Oreamuno, Rodrigo Facio, Isaac Felipe Azofeifa y los artistas Max Jiménez y Francisco Amighetti, quienes compartieron sus ideas, realizaron ilustraciones y publicaron sus textos plásticos y escritos. 
Amighetti formó parte de una generación de intelectuales y artistas preocupados por conformar una identidad nacional, una imagen de nación. En su época de juventud, formó parte del grupo de "La Nueva Sensibilidad" constituido por Teodorico Quirós, Fausto Pacheco, Luisa González de Sáenz, Francisco Amighetti, Manuel de la Cruz González y Francisco Zúñiga. Con ellos se inicia la Generación Nacionalista, que aborda como tema principal el paisaje nacional y, específicamente, la casa de adobe como tema característico. Si bien Amighetti en su temática se acercó a las búsquedas de la Generación Nacionalista, sus textos plásticos se distinguieron por ir más allá de la representación del hábitat del campesino para involucrarse con el contexto humano.

En sus textos poéticos, que serán intratextos de sus obras plásticas y viceversa, se van incorporando también las inquietudes sociales de un grupo de artistas que compartieron una generación entre los primeros años de este siglo. Esta generación de poetas, según Carlos Francisco Monge en su libro Antología Crítica de la Poesía en Costa Rica, estaba integrado por Max Jiménez, Fernando Centeno Güell, Arturo Echeverria Loría, Isaac Felipe Azofeifa, Fernando Luján, Alfredo Cardona Peña, Alfonso Ulloa Zamora y Francisco Amighetti. Así, su poesía y sus textos plásticos se nutren de las características estéticas de la "generación de prevanguardia", como la denomina Monge al referirse a la producción poética de esta generación.

\footnotetext{
Con su obra se establecieron relaciones directas con los movimientos históricos de vanguardia en Europa; y sobre ello nada despreciables resultaron los oportunos y fructíferos viajes de Max Jiménez a Buenos Aires, Santiago de Chile y París, Azofeifa a Santiago, Cardona Peña a México, Amighetti a Estados Unidos, México o Buenos Aires, Centeno Güell a Madrid, con todo lo cual la poesía (y en general el arte) de Costa Rica consolida la salida al exterior, y en particular con la ebullición y consecuencias de la vanguardia literaria (Monge 1992: 23).
}

Estos se caracterizaban por una asimilación de las vanguardias y una preocupación humanista, con lo que trataban de penetrar en el alma de los sujetos que intervenían en el intercambio simbólico social.

Las representaciones del espacio rural, idílico, dan paso a la ciudad como espacio estético pleno de vínculos y significaciones sociales, donde aparece el sujeto social como un protagonista ubicado entre el paso del tiempo y la vida cotidiana que enfrenta al ser humano en la angustia existencial.

\footnotetext{
Para el sujeto prevanguardista el mundo es su ciudad, y en ella el ser humano vive desamparado en medio de la ráfaga del tiempo; y desde la incertidumbre y el abandono, transfigura la realidad histórica. El abanico temático que se despliega a partir de este modo de representar la realidad es amplio y variado, pero corresponde a un núcleo ideológico principal la reorganización de un mundo a partir de la clausura de otro ya en extinción (Monge 1992: 24).
}

Ya sea en sus textos Francisco en Harlem y Francisco y los caminos o en Francisco en Costa Rica, aparece siempre la alusión a la patria; aunque en los dos primeros se describe un ambiente cosmopolita, se recurre al interdiscurso de la patria a modo de comparación y de añoranza. 


\begin{abstract}
No conocía ciudades grandes, Buenos Aires era la primera. En algunas esquinas el tránsito alcanzaba proporciones de sonora catástrofe con sus tranvías desbocados. En Costa Rica eran pequeños e iban chirriando hacia el poniente, en mi ciudad rodeada de montañas (Amighetti 1993: 39).
\end{abstract}

En la construcción de sus textos se desarrolla un vínculo con el contexto social: son textos escritos con un carácter autoreferente, a modo de una autobiografía ubicada en el torrente cotidiano que se detiene en el espacio textual. Este texto literario es un medio para preservar la imagen del pasado, de sus viajes, de su propia historia personal, las tradiciones y costumbres, pero también está inmerso dentro del esfuerzo conjunto de los intelectuales de su época para proyectar ese yo colectivo que permitiría reforzar la imagen de nación. Indudablemente, aunque sus textos traten de asuntos testimoniales, estos trascienden el nivel de la representación de lo personal para rescatar los valores y contradicciones de la memoria colectiva en su lucha para enfrentar lo cotidiano.

Este es el discurso que encontramos en el texto plástico Friso de los observadores observados, en el que la mirada de los otros establece el control social y permite la conformación de los valores que identifican los grupos humanos.

Así, es la mirada de los otros a través del yo, y de un yo que se establece en la mirada de los otros, que le permite tomar conciencia de su papel social como artista comunicador. Sus textos se construyen con un lenguaje llano y accesible y en su superficie son asimilados socialmente como si esperara la respuesta estética en el interior de ciertos códigos de lo social. En otras palabras, su trabajo se inserta dentro de las prácticas discursivas ideológicas, que pretenden rescatar la diferencia como nación con respecto a los otros y participar en la conformación de una memoria colectiva. Esta preocupación no sólo es del artista, se trata de una necesidad ideológica, un reto social que para Joaquín García Monge no es tan sencillo:

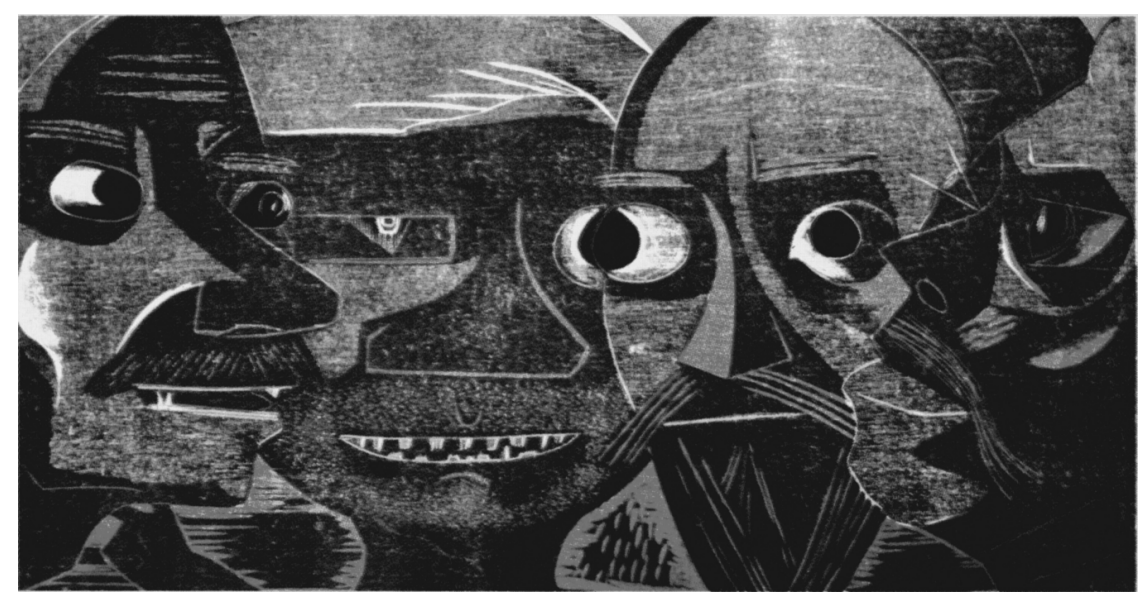

Figura 1

Friso de los observadores observados. Xilografía. 1972. 
Amighetti asume el reto de la mirada de lo cotidiano: es un observador social que asume una posición crítica ante su entorno, lo cual se evidencia en sus textos artísticos. En estos, el arte y la vida conforman un entramado textual que le permite conjuntar su autobiografía y su consciencia artística, como dos enfoques inseparables.

Su memoria le permite retener un conjunto de "ahoras" producto de ese ser ahí, momentos cruciales de la vida cotidiana para interpretarlos y crear una sensación de temporalidad en la reconstrucción y lectura del fenotexto.

\footnotetext{
Sin lugar a dudas, Francisco Amighetti fue copartícipe de la riqueza de una época que sumió a los creadores latinoamericanos en un cuestionamiento de base: su propia identidad latinoamericana de cara a los movimientos vanguardistas europeos... (González 1998: 6).
}

Las imágenes artísticas de Amighetti provienen de momentos de un pasado que fue su presente. Vivió durante el siglo XX y fijó en su memoria el vertiginoso desarrollo de la ciencia y la tecnología: cambios en la imagen del mundo y la producción artística, caracterizada por la experimentación creativa. Pero también es esta una época de conflictos sociales, a escala nacional y planetaria, de cambios en los límites y las fronteras de las naciones, de confrontaciones sociales y de muerte, así como de una explotación desmedida de la naturaleza, y de una irrefrenable internacionalización que dificulta los regionalismos y nos lleva a una globalización de la economía por bloques: ya no somos uno u otro, somos un bloque de países.

El cambio de siglo fue una época de rupturas en la historia social y cultural de Costa Rica. Sin embargo, la idea de una nación y la conformación de la unidad nacional fueron los incentivos para la evolución del concepto de la patria, que en Amighetti se fundamenta en la identidad y la imagen idealizada del pasado que se añora, pero en el que aparece la crítica social, como si todo tiempo pasado no fuera el mejor.

Así se evidencia en su obra mural La agricultura, realizada en la antigua Casa Presidencial a su regreso de México, a donde viajó para estudiar la técnica mural en la Escuela La Esmeralda. En este texto, la imagen de la patria aparece como una fértil mujer integrada a la tierra; la agricultura y la patria se unen en el concepto gráfico. Así, la tierra-patria que se cultiva con esmero es fuente de fertilidad; la tierra, la madre, la mujer son el origen de la vida, lo cual, además, nos remite al texto fundamental del desarrollo de la identidad: el Himno Nacional (1903), texto básico en la conformación de un modo de ser costarricense: labriego sencillo.

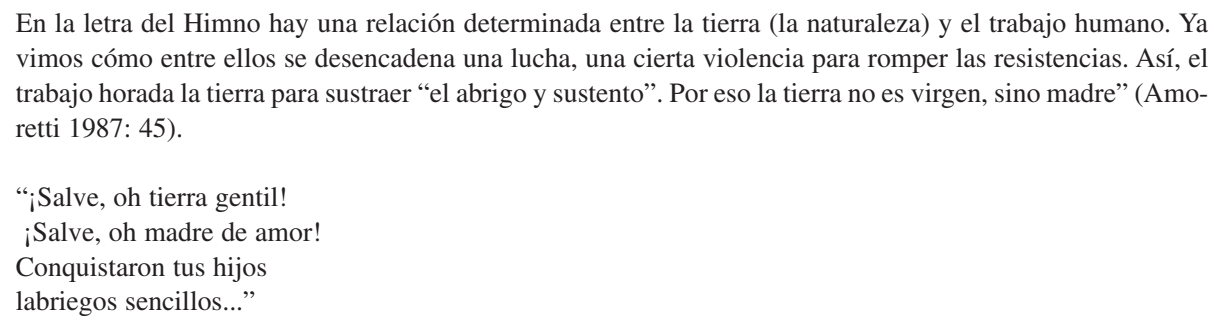

En el mural de Amighetti, el labriego sencillo es el protagonista en la construcción ideológica de lo nacional, pues exalta la generosidad de la tierra en el espacio histórico que sirve de anclaje sociocultural a la idea de la patria. 
En lo que se refiere a Costa Rica, investigadores como Álvaro Quesada o María Amoretti vislumbran ese surgimiento de la apropiación del territorio con la emergencia de una "conciencia" nacional y la concreción de un ser costarricense en términos de su relación con la tierra, tal y como Amoretti lo demuestra en su análisis del Himno Nacional, en donde reconfigura el significado del "labriego sencillo" a partir del tópico del elogio de la tierra... (Chen 1997: 25).

En La agricultura, el elogio de la tierra y del trabajo encuentra en el intertexto del Himno Nacional un paralelismo conceptual con la construcción ideológica de la patria, que tiene como eje al labriego sencillo, el cual horada la tierra para lograr su sustento.

La tierra también es el escenario de la propia conformación en la temporalidad, como lo manifiesta Gabriela Mistral (1931: 172) en uno de sus artículos en Repertorio Americano:

La tierra es el sostén de todas las cosas...Las cosas más visibles y las invisibles descansan sobre ella, desde la más pesada, como el vulgar metal, hasta la fina como la canción regional; la santa nutridora hace salir de ella lo mismo el clásico café que el pensamiento de Hostos.

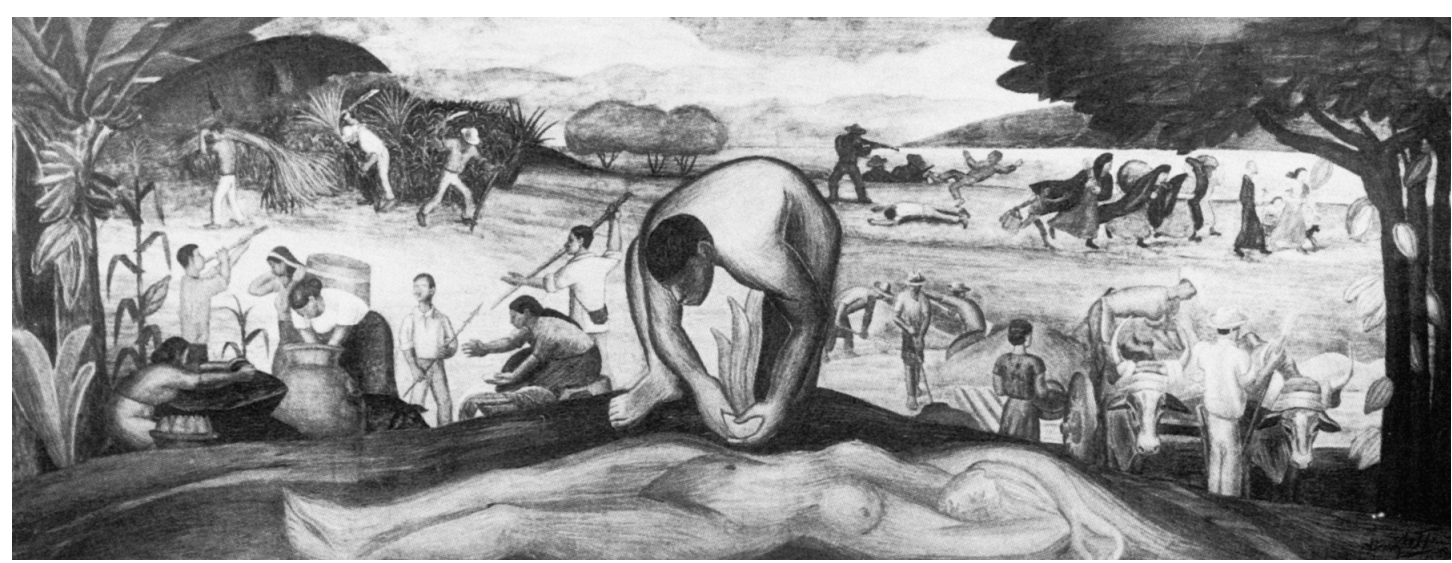

Figura 2

La agricultura. Mural al fresco

Es inevitable señalar el intertexto del poeta griego Hesíodo, en el que se representa a Pandora, divinidad de la tierra y la fecundidad, de la producción del alimento y la reproducción de la vida.

A diferencia de la abundancia de la tierra en la Edad de Oro, en la Edad de Hierro la humanidad está condenada al trabajo, la vejez y la muerte. Debe trabajar la tierra para obtener su sustento.

\footnotetext{
Ya no es la abundancia espontánea que en la edad de oro hacía brotar el suelo, por la sola virtud de soberanía justa, sin intervención ajena, a los seres vivos y sus alimentos; en adelante es el hombre quien deposita su vida en el seno de una mujer, lo mismo que afanándose sobre la tierra, hace germinar de ella los cereales. Toda riqueza adquirida debe ser pagada con el esfuerzo invertido como contraparte. Para la raza de Hierro, la tierra y la mujer son al mismo tiempo principios de fecundidad y potencias de destrucción; agotan la energía del hombre dilapidando sus esfuerzos, desecándolo por vigoroso que sea, entregándolo a la vejez y la muerte al depositar en el vientre de ellas el fruto de sus penas (Lapassade et al 1966: 33).
} 
El paralelismo del intertexto de Hesíodo con el mural de Amighetti está mediatizado por la intertextualidad bíblica del Génesis.

En el sudor de tu rostro comerás el pan, hasta que vuelvas a la tierra, porque de ella fuiste tomado: Porque polvo eres, y al polvo serás tornado (Génesis, III. 19).

Y sacóle Jehová del huerto del Edén, para que labráse la tierra, de que fue tomado (Genésis, III. 23).

En el mismo concepto del origen de la vida que germina, está presente el concepto de la muerte, el principio y el fin, en un espacio temporal de luchas históricas y gestas heroicas. Momentos cruciales de la patria que se forja en el trabajo como el ideal de la construcción ideológica. Así, del texto se deduce un interdiscurso económico: el trabajo como signo del progreso, la carreta que marcha en dirección frontal reafirma el paradigma del progreso y la evolución, recoge a su paso los productos de exportación, fruto del esfuerzo, del trabajo tenaz que encontramos en el intertexto ya citado: "... la lucha tenaz, de fecunda labor..."

La planta que siembra el personaje central forma parte del proceso de vida que involucra su propio final, el mismo proceso de trabajo contiene un consumo del tiempo en aras de la patria, que transforma la lucha por un ideal en un hecho histórico.

Toda nuestra cultura no es más que un inmenso esfuerzo para disociar la vida de la muerte, conjurar la ambivalencia de la muerte en beneficio de la reproducción de la vida como valor, y del tiempo como equivalente general. Abolir la muerte, tal es nuestro fantasma que se ramifica en todas direcciones: el de la supervivencia y la eternidad para las religiones, el de la verdad para la ciencia, el de la productividad y la acumulación para la economía (Baudrillard 1980: 170).

Así, la construcción pictórica en el texto plástico tiene como base conceptual la idea de nacimiento y fertilidad de la tierra, como el sitio de la patria donde tiene origen el nacimiento y la gesta; pero, a la vez, la esencialidad de un pueblo eminentemente agrícola, cuyo desarrollo sociopolítico y cultural está basado principalmente en la producción del café.

\footnotetext{
El nacimiento, como suceso social, es el inicio de la vinculación, es decir de toda identidad personal. En cuanto tal, el nacimiento desencadena la creación de una urdimbre de relaciones en las que se configura la identidad del sujeto. De tal modo que el nacimiento se convertirá en un punto de referencia para la transparencia u opacidad que el sujeto tenga de sí mismo (González 1994: 141).
}

Este volver al origen, a buscar en el pasado las raíces de una identidad cultural, en medio de la explosión de las vanguardias, tuvo su efecto en el movimiento muralístico mexicano, que enarboló la bandera del compromiso del arte con los problemas sociales y políticos y tuvo una gran influencia en toda Latinoamérica.

\footnotetext{
Bajo la influencia del muralismo mexicano Amighetti adquiere un importante compromiso americanista y social, que logra amalgamar, como lo hicieran sus homólogos mexicanos, las tradiciones muralistas tanto precolombinas como europeas.

Al retornar a Costa Rica, Amighetti encuentra en el muralismo un eficaz medio para despertar en el costarricense una sensibilidad adormecida y a la vez un medio representativo idóneo con el cual llevar al pueblo, de forma sintética, temáticas de índole didáctica y artística (González 1998: 6).
}

La búsqueda de nuevas visiones de lo nacional fueron preocupaciones constantes compartidas por sus contemporáneos en la literatura y las artes plásticas. 
Tenemos por ejemplo, la famosa polémica de principios de siglo entre Gagini y Ricardo Fernández Guardia sobre lo que era o no regional, entre lo que era o no identidad en la literatura costarricense.

\begin{abstract}
La incorporación de lo subjetivo, lo cotidiano, lo popular, o el rescate de la vivencia existencial e íntima; la ampliación de los límites del realismo academicista con su rigidez objetiva, su ampulosidad y su respeto a los moldes clásicos para introducir la estilización y la deformación grotesca de las imágenes ...Por primera vez en Costa Rica se puede hablar de una promoción que reúne escritores, pintores y escultores, que comparten luchas y preocupaciones comunes, una mayor conciencia de la especificidad del arte y del artista, una mayor apertura a los experimentos y transformaciones de su época y una posición más crítica con respecto a la vida cultural costarricense (Quesada 1998: 158).
\end{abstract}

En síntesis, la propuesta amighettiana en torno a la identidad nacional tiene como eje el ser humano, ese yo vinculado a la tierra y, por ende, a la agricultura en esencia; pero, sobre todo, el reencuentro con el ser humano en su dimensión existencial, establecida por el individuo con su temporalidad, construyendo su vínculo con el mundo y, por tanto, su historia individual y colectiva. Es a través de su experiencia de vida, del saber de lo cotidiano, de la mirada de los otros y su propia mirada como ser finito que adquiere el concepto que alimenta toda su producción artística, en la que dialogan el Himno Nacional, los textos literarios de Magón, Joaquín García Monge, Gagini, Aquileo Echeverría, Arturo Aguëro Chaves, los textos pictóricos de la generación nacionalista y sus intratextos en diálogo con los más altos valores del ser humano en general y del costarricense en particular.

Así se configura "ese modo de ser costarricense", cuya construcción solo es aprehensible en los textos musicales, pictóricos y literarios dirigidos a la identidad del ser que interactúa cotidianamente en el espacio de la patria.

\title{
Bibliografía
}

Amighetti, Francisco. 1989. Francisco Amighetti. San José. Editorial Universidad de Costa Rica.

1993. Obra Literaria. San José. Editorial Universidad de Costa Rica.

Amoretti, María. 1987. Debajo del Canto. San José. Editorial Universidad de Costa Rica.

Baudrillard, Jean. 1980. El intercambio simbólico y la muerte. Barcelona. Editorial Monte Ávila.

Chen Sham, Jorge. 1997. La apropiación del espacio o la topofilia del tico en "Esta tierra en nuestra tierra de Alfonso Chase". En Káñina, Revista de Artes y Letras. XXI (2): $25-30$

González, Alfonso. 1994. Costa Rica, el discurso de la patria. San José: Editorial Universidad de Costa Rica. 
Gonzáles, Mercedes. 1998. Francisco de los Caminos. Crónica de una vivencia latinoamericana. En La Nación: Suplemento Áncora. 22 noviembre: 6.

Herra, Rafael Ángel. 1987. El desorden del espíritu. San José: Editorial Universidad de Costa Rica.

La Biblia. 1995. Madrid: Editorial Verbo Divino.

Lapassade Georges et al. 1975. Las nociones de estructura y génesis. Buenos Aires: Editorial Nueva Visión.

Mistral, Gabriela. 1931. Conversando sobre la tierra. En Repertorio Americano. XXIII (11)

Monge, Carlos Francisco. 1992. Antología crítica de la poesía de Costa Rica. San José: Editorial de la Universidad de Costa Rica.

Montero, Carlos Guillermo. 1988. Amighetti 60 años de labor artística. San José: Museo de Arte Costarricense.

1988. Amighetti Expresionista. Tesis de Licenciatura: Universidad de Costa Rica.

Mora, Arnoldo. 1993. Historia del pensamiento costarricense. San José: Editorial Universidad Estatal a Distancia.

Nietzsche, Federico. 1993. Más allá del bien y el mal. México: Editores Mexicanos Unidos.

Quesada, Álvaro. 1998. Uno y los otros. San José: Editorial de la Universidad de Costa Rica.

Zamora Álvaro. 1998. El claroscuro de una vida. En La Nación: Suplemento Áncora. 22 de noviembre: 1 . 